\title{
Sneaking the dark side of brand engagement into Instagram: The dual theory of passion
}

\author{
Shintaro Okazaki ${ }^{a, *}$, Florian Schuberth ${ }^{\mathrm{b}}$, Takumi Tagashira ${ }^{\mathrm{c}}$, Victoria Andrade ${ }^{\mathrm{a}}$ \\ ${ }^{a}$ King's College London, King's Business School, 30 Aldwych, London WC2B 4BG, UK \\ ${ }^{\mathrm{b}}$ University of Twente, Faculty of Engineering Technology, Department of Design, Production and Management, Drienerlolaan 5, 7522 NB Enschede, the Netherlands \\ ${ }^{\mathrm{c}}$ Hitotsubashi University, Hitotsubashi University Business School, 2-1 Naka, Kunitachi-shi, Tokyo 186-8601, Japan
}

\section{A R T I C L E I N F O}

\section{Keywords:}

Brand engagement

Compulsive behaviors

Materialism

Narcissism

Social media

Vanity

\begin{abstract}
A B S T R A C T
The dual theory of passion indicates harmonious passion leads to obsessive passion. This study contemplates that brand engagement (harmonious passion) leads to compulsive behavior (obsessive passion) in two ways: compulsive social media use and compulsive buying. Echoing prior passion research, we posit that three personality traits associated with compulsive behaviors - vanity, narcissism, and materialism-moderate these relationships, while technostress mediates the effect of compulsive social media use on compulsive buying. We conduct an online survey in the UK with 527 consumers, using structural equation modeling for data analysis. The results indicate vanity moderates the brand engagement $\rightarrow$ compulsive social media use relationship: as vanity intensifies, the effect of brand engagement on compulsive social media use increases. Likewise, narcissism moderates the compulsive social media use $\rightarrow$ compulsive buying relationship. In contrast, materialism moderates neither the brand engagement $\rightarrow$ compulsive social media use, nor the compulsive social media use $\rightarrow$ compulsive buying relationship.
\end{abstract}

\section{Introduction}

The engagement concept has received much attention in the past decades (e.g., Alvarez-Milán, Felix, Rauschnabel, \& Hinsch, 2018; Brodie, Hollebeek, Jurić, \& Ilić, 2011; van Doorn et al., 2010). Engagement is defined, for example, as emotional purposes that sustain commitment (Warde, 2005). Prior research distinguishes different types of engagement concepts, including customer engagement, brand engagement, online consumer engagement, and online brand community engagement, among others (Alvarez-Milán et al., 2018).

This study focuses on the outcomes of brand engagement. As a broad definition, brand engagement refers to "a customer's behavioral manifestations that have a brand or firm focus, beyond purchase, resulting from motivational drivers" (van Doorn et al., 2010, p. 254), which includes word of mouth, recommendations, helping other customers, blogging, and writing reviews. As a driver of psychological outcomes, this study specifically views brand engagement as part of consumers' self-concept (Sprott, Czellar, \& Spangenberg, 2009). Such strong psychological attachment to the self creates a strong connection between consumers and brands.
Prior research suggests that brand engagement leads to more favorable brand-related attitudes and behaviors, and acts as a positive indicator in terms of brand loyalty and usage (Alvarez-Milán et al., 2018; Brodie et al., 2011; van Doorn et al., 2010). However, little attention has been paid to its dark side. Might extremely engaged customers end up using brands' social media in an abusive manner? In psychology, the dual theory of passion (Vallerand et al., 2003) contrasts harmonious passion and obsessive passion. In this framework, this study envisages brand engagement as harmonious passion and examines its obsessive counterpart: compulsive behaviors.

Psychologists view compulsive behaviors as a psychiatric disorder (Aladwani \& Almarzouq, 2016). For example, an increasing number of people are becoming obsessed with social networking sites, neglecting their own well-being. By the same token, compulsive buying has been viewed as a means of achieving short-term gratification due to low levels of self-esteem, high levels of depression, and a variety of anxiety conditions and obsessions (Faber, Christenson, de Zwaan, \& Mitchell, 1995). Such compulsive behaviors are thought to produce certain stress, namely, technostress (Weil \& Rosen, 1997), which may influence the effect of compulsive social media use on compulsive buying.

\footnotetext{
* Corresponding author.

E-mail addresses: shintaro.okazaki@kcl.ac.uk (S. Okazaki), f.schuberth@utwente.nl (F. Schuberth), takumi.tagashira@r.hit-u.ac.jp (T. Tagashira), victoria. andrade@kcl.ac.uk (V. Andrade).
} 
Furthermore, this study contemplates three personality traits that affect the links between compulsive behavior and brand engagement: vanity, narcissism, and materialism. These personality traits are closely related to one another both empirically and theoretically (Netemeyer, Burton, \& Lichtenstein, 1995; Richins, 2004).

The contributions of this article lie mainly in three areas. First, this study sheds light on the importance of the dual theory of passion in brand engagement research. Addressing compulsive behaviors as a negative side of brand engagement in a context of a harmonious versus obsessive passion dyad provides new knowledge to the literature. Second, exploring the impact of personality traits on the effects of brand engagement demonstrates when and why certain compulsive behaviors occur on social media. Both compulsive social media use and compulsive buying have become an important societal issue that needs to receive more attention from social marketers and policymakers. Our study marks a first step in this direction. Third, this study addresses these issues on one of the fastest growing social media platforms: Instagram. Despite the costs associated with the generalizability of the findings, Instagram provides an extremely interesting research setting, as it is one of the few visually based social media platforms where consumers' brand engagement and related concepts may develop in a very unique way, compared with other social media platforms, such as Facebook and Twitter.

Based on the dual theory of passion and the impact of personality traits on passion, we posit a series of hypotheses. To test them, we analyze data from 527 general consumers in the UK via structural equation modeling. The results indicate that vanity, narcissism, and materialism play rather different roles in the moderation of the relationship between brand engagement and compulsive social media use.

\section{Theoretical framework}

\subsection{Dual theory of passion}

This study envisages the dark side of brand engagement from the perspective of the dual theory of passion. According to this theory, passion is defined as "a strong inclination toward an activity that people like, find important and in which they spend time and energy on a regular basis" (Vallerand et al., 2003, p. 757). Passion is often juxtaposed with reason and self-control as an emotion that can create problematic behaviors-that is, passion can drive behavior toward achievement, but it can also prevent purposeful behavior from occurring. This dualism can be regarded as a distinctive feature of passion.

According to this theory, passion is regarded as the investment of time and energy in an interesting and valuable activity (Vallerand, 2008). Such activity will be "internalized in the person's identity to the extent that these are highly valued and meaningful for the person" (Vallerand, 2010, p. 102). Depending on how the passionate activity has been internalized into one's identity, we can distinguish two types of passion: obsessive and harmonious. Harmonious passion creates a strong motivation to engage in an activity, and it occurs when an individual recognizes an activity as important without granting it overwhelming power; here, the person controls the activity. In contrast, obsessive passion creates an uncontrollable urge to engage in an activity, granting it power over an individual. Here, the activity controls the person. Prior research indicates that harmonious passion and obsessive passion are two qualitatively different constructs rather than two points on the same continuum (Mageau, Vallerand, Charest, \& Salvy, 2009). Overall, harmonious passion allows for psychological adjustment and creates positive affect, while obsessive passion is detrimental to a person's wellbeing and creates negative emotional states (Vallerand, 2008).

From the perspective of the dual theory of passion, brand engagement and compulsive behaviors mirror harmonious passion and obsessive passion, respectively. Exploring this dual nature of brand engagement seems not only important, but also necessary, due to the increasing number of abusive social media users and obsessive shoppers.
Yet, empirical research on the relationship between brand engagement and compulsive behaviors has been extremely scarce.

\subsection{Impact of personality on passion}

Vallerand (2010) emphasizes that personality could be an important driver of the internalization process of passionate activity. Prior empirical research seems to echo this theory. For example, Balon, Lecoq, and Rimé (2013) found that, among the Big Five personality dimensions, Conscientiousness, Extraversion, Neuroticism, and Openness were positively related to harmonious passion, while Agreeableness was negatively related to obsessive passion. The authors rationalize this negative relationship, as obsessively passionate individuals tend to run into conflicting situations not only with other life activities but also with people not directly engaged in the favorite activity. In this regard, Vallerand et al. (2003) distinguish intrinsic and extrinsic motivations of passion. Intrinsic motivation, which is more associated with harmonious passion, involves engaging in an activity out of pleasure and enjoyment. In contrast, extrinsic motivation, which is more associated with obsessive passion, encompasses engaging in the activity not out of pleasure, but "to obtain something outside the activity" (p. 761). All these findings seem to indicate that, in contrast to harmonious passion, obsessive passion overwhelms one's identity as the activity escapes from one's control.

Furthermore, Lafrenière, Vallerand, and Sedikides (2013) found that, when an individual feels an insecure sense of self, obsessive passion for an activity benefits more from self-enhancement in terms of life satisfaction. Self-enhancement occurs when people evaluate themselves more favorably than objective facts justify. Relevant to our research, this finding indicates that obsessively passionate individuals may engage in self-enhancing behaviors by indulging in showing their achievement or appearance more positively than otherwise possible. We believe that one of the drivers of such self-enhancement can be a vain, narcissistic, or materialistic personality. Fig. 1 summarizes our conceptual framework.

\section{Proposed model}

\subsection{Core variables: Brand engagement and compulsive behaviors}

\subsubsection{Brand engagement}

In an attempt to predict consumers' general engagement with brands, Sprott et al. (2009) developed a scale to measure brand engagement in self-concept, which refers to "an individual difference representing consumers' propensity to include important brands as part of how they view themselves" (p. 92). A theoretical rationale behind brand engagement in self-concept is that consumers tend to recognize a series of brands as a part of their "self-schemas representing stable knowledge structures about the self that organize incoming self-related information and help people make sense of themselves in their environment" (p. 92).

Conceptually, brand engagement in self-concept is similar to emotional brand attachment (Malär, Krohmer, Hoyer, \& Nyffenegger,

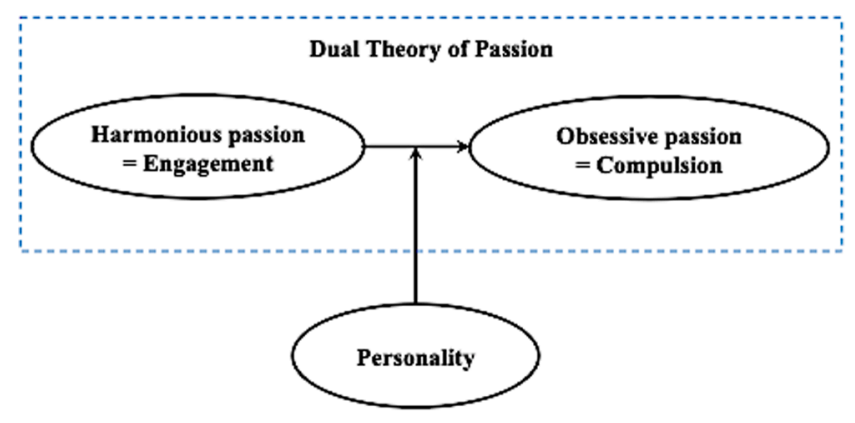

Fig. 1. Conceptual framework. 
2011), which is defined as emotional connection with the brand. However, they differ from each other in that brand engagement in selfconcept addresses the nature of self-brand connections, while emotional brand attachment is viewed as part of the multifaceted nature of emotionally charged relationships with brands (Belk, 1988; Fournier, 1998), consisting of affection, connection, and passion. This study adopts the former, as we are mainly interested in the generalized tendency to include brands as a part of one's self-concept.

In a computer-mediated context, this dimension of brand engagement implies a potential emotional bond developed through continuous and repeated contact via social media. However, even among frequent users of social media, some people develop self-schemas about their relationship with brands while others may not. Yet, brand engagement through social media has an important impact on brand-related consumer attitudes and behaviors.

\subsubsection{Compulsive social media use}

Initially described only as Internet addiction (Young, 1996), recent technological developments have created the need to extend the concept to include several forms of problematic behaviors and engagement types, from compulsive Internet use (Billieux, Rochat, Rebetez, \& Van der Linden, 2008) to compulsive social media use (Rosen, Whaling, Rab, Carrier, \& Cheever, 2013; Sheldon \& Bryant, 2016). Currently, terms such as addictive, compulsive, and dependent are used interchangeably to refer to the same problematic behavior (Aladwani \& Almarzouq, 2016; Andreassen et al., 2016; Quinones-Garcia \& Korak-Kakabadse, 2014). For the purpose of the present study, we define compulsive social media use as the spontaneous and unintentional behavior that seeks social media platforms through Internet access and devices, resulting in harmful consequences comparable to those of addiction (Bernardi \& Pallanti, 2009).

Compulsive social media use is a problematic behavior featuring the abusive use of the Internet and characterized by a lack of control, with harmful consequences to social interactions (Caplan, 2003). Specifically, its symptoms are dominating thoughts of social media use, increased tolerance and the need to increase use to produce the same excitement, withdrawal symptoms when there is a pause in social media access, loss of control when trying to stop, and inevitable relapse into old habits (Quinones \& Kakabadse, 2015). Also, in the compulsive context, social media is used as a mood regulator to reduce negative feelings of guilt, anxiety, or restlessness (Andreassen et al., 2016). Consequently, compulsive social media users will engage with technology and social media to improve their moods and experience of self (Porter \& Kakabadse, 2006).

Compulsive social media usage can have more of an effect on those with previous mental health issues, generating online behaviors that can have harmful consequences. For instance, a study revealed that individuals who suffer from depression are more likely to prefer online versus face-to-face social interactions (Caplan, 2003). In another study, social anxiety predicted a preference for online social interactions (Caplan, 2007). Additionally, compulsive social media users were likely to experience low self-esteem and were more likely to turn to social media outlets to feel better (Blachnio et al., 2016). Psychological ailments such as obsessive-compulsive disorder, depression, attention deficit or hyperactivity disorder, and narcissism have been shown to significantly contribute to a problematic use of social media (Malik \& Khan, 2015). Thus, there is a strong relationship between previous psychological issues and social media compulsion. This leads to our first hypothesis:

H1. Brand engagement positively affects compulsive social media use.

\subsubsection{Compulsive buying}

Some individuals try to manage depressive feelings (Lejoyeux, Tassain, Solomon, \& Ades, 1997), negative life circumstances, stress, and even their need for affection (O'Guinn \& Faber, 1989) by engaging in compulsive buying. Compulsive buying is characterized by persistent obsessive thoughts about purchasing products, poor impulse control associated with spending money, and severe social, psychological, and economic consequences (Piquet-Pessoa, Ferreira, Melca, \& Fontenelle, 2014). It reflects elements of compulsion, a ritualistic solution to obsessive, uncontrolled thoughts that arise in certain people's minds (Hollander \& Allen, 2006); and of impulse control, a lack of control over an irresistible temptation, creating the impulse to perform harmful behavior (Ridgway, Kukar-Kinney, \& Monroe, 2008).

Research shows that compulsive buying is characterized by a prebuying emotional state and post-buying behaviors. Overall, the emotions experienced before the purchase are negative, including sadness, irritability, anxiety, and boredom (Faber \& Christenson, 1996), followed by an uncontrollable buying binge aiming to alleviate these negative emotions (Koran, Faber, Aboujaoude, Large, \& Serpe, 2006). An overwhelming negative feeling inevitably follows the buying process (Faber, O'Guinn, \& Krych, 1987) because it does not relieve compulsive buyers' long-term negative emotional states-the relief is only temporary (Miltenberger et al., 2003).

Compulsive buying occurs as a coping mechanism against everyday anxiety. It allows the individual to focus solely on the purchase process and block other negative feelings for a short period of time. The "high" experienced during the act of buying positively reinforces and increases the recurrence of compulsive buying (Darrat, Darrat, \& Amyx, 2016). Additionally, since compulsive buyers focus their attention solely on the present purchase task, they forgo the long-term consequences of their behaviors, which can lead to severe consequences such as debt and abuse of credit (Faber et al., 1987; Koran et al., 2006).

Compulsive buyers tend to exhibit specific qualities. In terms of demographics, they are usually younger and have on average a lower income than other consumers (Koran et al., 2006). Regarding psychological traits, one main characteristic is that compulsive buyers tend to have low self-esteem and low social desirability (Davenport, Houston, \& Griffiths, 2012; Ridgway et al., 2008). Also, they are more materialistic (Ridgway et al., 2008) and feel the urgency to reduce negative feelings through impulsive behaviors (Billieux et al., 2008). Interestingly, compulsive buyers are likely to engage in consumptionrelated peer communication (Baker, Moschis, Rigdon, \& Fatt, 2016).

Recent studies have focused on the effect that online retailing has on impulses and compulsive buying (Chan, Cheung, \& Lee, 2017; Vonkeman, Verhagen, \& van Dolen, 2017). This research has revealed that compulsive buyers have a stronger motivation to buy unobserved and to avoid social interaction, resulting in higher-than-average amounts of money spent online (Kukar-Kinney, Ridgway, \& Monroe, 2009). Additionally, researchers found that consumers who prefer brick-and-mortar stores have a lower tendency to engage in compulsive buying-more specifically, a preference for online retail is positively associated with compulsive purchasing (Kukar-Kinney, Ridgway, \& Monroe, 2012). At the same time, an urge for online impulse buying is more likely to occur in the context of local presence, or the feeling that online products are part of the buyer's offline world (Vonkeman et al., 2017). Considering that compulsive buyers are driven by hedonic, social, identity, and emotional motivations when shopping online, it follows that social media usage could facilitate and precipitate shopping if these platforms allow compulsive buyers to attain their goals.

H2. Compulsive social media use positively affects compulsive buying.

\subsection{Moderators: Vanity, narcissism, and materialism}

\subsubsection{Vanity}

The above-mentioned relationships among brand engagement, compulsive social media use, and compulsive buying are thought to be moderated by three personality traits, namely, vanity, narcissism, and materialism. These three traits are not only empirically but also theoretically related to one another (Netemeyer et al., 1995). 
From undergoing elective cosmetic surgery to fashion choices and makeup purchases (Workman \& Lee, 2010), a great variety of current consumer actions are instigated by vanity. Seen as increased self-esteem due to pride or beauty (Zilio-Abdala \& Vargas-Rossi, 2008), vanity is defined as "a fixation on physical appearance and achievement of personal goals" and "inflated" views of both (Netemeyer et al., 1995, p. 612). Namely, physical vanity and achievement vanity present distinct characteristics and perspectives within vain individuals.

Social interactions are easily accessible through social media. Previous studies have shown that high levels of vanity lead to higher preferences for online social gratification and recognition (Leung, 2013). Additionally, vain individuals will be more likely to engage (online and offline) with brands they perceive to be achievementgranting through purchases and interactions (Workman \& Lee, 2010). Today, social media platforms allow for sharing hedonic and conspicuous visual posts that indulge the needs of people with appearancerelated and achievement-granting vanity concerns.

Both the achievement and appearance aspects of vanity are linked to consumption practices. Achievement vanity is more associated with marketing activities related to materialistic outlets, such as brand relationships and engagement, whereas appearance vanity is associated with social media usage (Netemeyer et al., 1995). It follows that vanity could be a moderating factor between brand engagement and compulsive behaviors. More specifically:

H3. Vanity influences the entire process by which people fall into compulsive behaviors, including the strength of the effects of (a) brand engagement on compulsive social media use, and (b) compulsive social media use on compulsive buying.

\subsubsection{Narcissism}

The The American Psychiatric Association (2017) recognizes narcissistic personality disorder as an abnormal behavior pattern that includes elements of "grandiose exhibitionism" and "entitlement"; these translate into characteristics such as little empathy for others, arrogance, impulsivity, materialism, and feelings of superiority (Ackerman et al., 2011). Specifically, pathological narcissists display grave selfregulatory shortcomings, especially when faced with threats to their self-image (Pincus \& Lukowitsky, 2010). Narcissistic traits are not always pathological, since they allow individuals to create and maintain a positive self-image, but in certain conditions, they can create difficulties in having proper social interactions and healthy relationships (Ackerman et al., 2011).

Non-pathological narcissism has been associated with social media addiction (Andreassen, Pallesen, \& Griffiths, 2017). Research shows that narcissists use social media accounts differently; for instance, they would gladly accept unknown friend requests with the purpose of increasing their audience numbers, not their friends (Carpenter, 2012). In fact, narcissists will have a higher number of friends on Facebook and will actively try to increase their friend numbers (Buffardi \& Campbell, 2008). Additionally, narcissists are more likely to post self-promoting content, specifically, self-focused pictures or "selfies," than nonnarcissists (Bergman, Fearrington, Davenport, \& Bergman, 2011). Narcissists are also more likely to share their accomplishments on social media (Marshall, Lefringhausen, \& Ferenczi, 2015). Due to the selfpromoting, exhibitionist, and attention-seeking behaviors of narcissists, they have an increased vulnerability for compulsive social media use.

Research reveals that there is a significant relationship between compulsive buying and narcissism (de Bellis, Sprott, Herrmann, Bierhoff, \& Rohmann, 2016; Rose, 2007). In fact, narcissism has been shown to predict compulsive buying: individuals exhibiting narcissistic traits are more likely to engage in impulse buying (Cai, Shi, Fang, \& Luo, 2015). Additionally, narcissists and compulsive buyers share some characteristics such as impulsivity and materialistic tendencies, and both will engage in impulse purchases to improve their inner emotional states (Ackerman et al., 2011). For instance, narcissists are more likely to pursue and purchase special material possessions (personalized or customized) that they believe show off their (perceived) unique status (Lee, Gregg, \& Park, 2013); at the same time, compulsive buyers are more likely to engage in unplanned purchases to improve their moods and feelings of self-worth.

Even though narcissism has been associated with compulsive buying and with compulsive social media use, no studies have linked compulsive social media use and compulsive buying with narcissism. The present study aims to fill this literature gap and expand the knowledge of comorbid compulsions in the field of consumption. Therefore, we posit:

H4. Narcissism influences the process by which people fall into compulsive behaviors, including the strength of the effects of (a) brand engagement on compulsive social media use, and (b) compulsive social media use on compulsive buying.

\subsubsection{Materialism}

Often juxtaposed with narcissism, materialism is defined as a "set of centrally held beliefs about the importance of possessions in one's life" (Richins \& Dawson, 1992, p. 308). Prior research indicates that vanity and materialism are closely related. In a materialistic world, achievement is often equated with material possessions. In fact, materialism has been proposed as the behavioral manifestation of vanity due to the strong relationship between materialistic behavior and vanity traits (Netemeyer et al., 1995). Hence, materialistic individuals may tend to engage in behaviors to show off personal achievement via material possessions.

In contrast, the literature suggests that materialism may act as a buffer for low self-esteem. For example, Rindfleisch, Burroughs, and Wong (2009) found that when people were reminded of their unavoidable death, they tended to become more materialistic and sought strong connections to their brands as a response to existential insecurity - that is, they strove to improve their sense of self in times of crisis. Additionally, Li, Lu, Xia, and Guo (2018) recently concluded that materialism could compensate for low self-esteem in economically challenged individuals. These conclusions imply that materialistic individuals may become more engaged with brands to strengthen their self-esteem. As we pointed out, low levels of self-esteem are one of the key drivers of compulsive buying (Faber et al., 1995). Taken together, we hypothesize:

H5. Materialism influences the entire process by which people fall into compulsive behaviors, including the strength of the effects of (a) brand engagement on compulsive social media use, and (b) compulsive social media use on compulsive buying.

\subsection{Mediator: Technostress}

Today's online demands have taken a toll on individuals' well-being (Lee, Lee, \& Suh, 2016). All the new hardware (gadgets, tablets, smartphones, desktops, and laptops) and software (the cloud, Wi-Fi, social media platforms, apps, and updates) require careful attention and skillfulness for the user to be efficient in everyday life. Research surrounding information and communication technologies (ICTs) has uncovered a growing anxiety surrounding the introduction of new technology, termed "technostress" (Weil \& Rosen, 1997), which denotes the negative psychological state that arises from coping with and understanding ICTs' constant innovations (Ragu-Nathan, Tarafdar, \& Ragu-Nathan, 2008).

The characteristic mobility associated with technology adds to the technostress that consumers experience. For instance, individuals are perceived as always being "online" through their mobile gadgets, and regardless of their own realities, they are expected to reply efficiently to ICT requests (Ayyagari, Grover, \& Purvis, 2011). In fact, technostress has been shown to be associated with technology dependence (Mak, Nickerson, \& Sim, 2018) and reduced work productivity (Tarafdar, Tu, 
Ragu-Nathan, \& Ragu-Nathan, 2007). Additionally, young individuals are more likely to suffer from "fear of missing out," or the need to be perpetually online and connected with others, especially through platforms that enable status comparisons, which has been linked to userelated stress in a social media context (Beyens, Frison, \& Eggermont, 2016). Thus, technostress exists in both work- and leisure-related use of information technologies.

The widespread use of technological innovations can give rise to problematic behavioral outcomes. Moreover, technostress is more likely to occur when compulsive smartphone use develops (Lee, Chang, Lin, \& Cheng, 2014) and when there is compulsive social media use (Hsiao, Shu, \& Huang, 2017). That is, the constant need to check and update social media profiles, to engage socially, and to keep followers' interests through mobile connectivity will likely increase an individual's (techno) stress. Given that technostress seems to increase when compulsive behavior occurs, it follows that compulsivity and stress are associated factors that will influence consumer behaviors in an online context. Specifically, we posit that technostress acts as a mediator that increases the possibility of driving compulsive social media users to compulsive buying. Fig. 2 summarizes our research model and hypotheses.

H6. The effect of compulsive social media use on compulsive buying is mediated by technostress, such that greater compulsive social media use increases the level of technostress, and greater technostress increases compulsive buying.

\section{Method}

\subsection{Survey design}

The site of this study is the UK, a country with a high percentage of Internet addiction, and where public hospitals are preparing to launch the first ever National Health Service-funded Internet addiction center for young people and adults (Marsh, 2018). In designing the study, we began by developing a survey instrument with Qualtrics survey software and included three sets of questions. First, we included general Instagram usage questions (frequency of usage, account check, photo upload, etc.). Next, we asked the respondents the name of the brand they psychologically associate with themselves. Specifically, we included the following brand elicitation task, which Grisaffe and Nguyen (2011) used:

We are interested in your relationship with a brand that you feel very fond of and emotionally attached to. It can be any brand, as long as you have a very strong, special bond to it...... Please think of a brand that you feel emotionally attached to. In the space provided below, please describe briefly what brand it is, how long you have purchased this brand, and why you feel emotionally attached to it.

According to this instruction, the respondents wrote down the name of the brand. Those who did not respond to this elicitation task were eliminated from the final dataset. After this brand elicitation task, we included measures for each of the constructs (compulsive social media use, vanity, narcissism, materialism, compulsive buying, and technostress). The questionnaire concludes with demographic questions about gender, age, occupation, educational levels, and annual income.

\subsection{Sample}

The sample consists of general British consumers. We ensured that the sample reasonably represented the general British population in terms of gender and age proportions. We omitted people older than 50 years, due to low Instagram usage. Table 1 contains a summary of the characteristics of the 527 valid survey responses.

\subsection{Measures}

The survey consisted of two parts: (1) questions related to demographic information (sex, age, and occupation), and (2) items related to the research constructs, all of which were adopted or adapted from prior research. We have provided a list of questionnaire items with their sources in the Appendix.

\section{Data analysis}

We conducted the analysis in MPlus (Version 8; Muthén \& Muthén, 2017). The exploratory factor analysis (EFA) was conducted using the maximum-likelihood (ML) estimator. To estimate the confirmatory factor analyses (CFAs) and the linear structural equation model, we employed the robust maximum likelihood (MLR) estimator. The nonlinear structural equation model was estimated using latent moderated structural equations (LMS; Klein \& Moosbrugger, 2000). Moreover, standard quality indicators, such as Cronbach's alpha, composite reliability, average variance extracted, and the heterotrait-monotrait ratio of correlations, are not calculated by default in MPlus. Therefore, we used the statistical programming environment R (R Core Team, 2018) for their calculation. Figs. 3 and 4 were created using the R package ggplot2 (Version 3.2.0; Wickham, 2016).

\subsection{Common method variance}

In self-report surveys, common method variance (CMV) refers to the systematic variance shared among the measures that is attributed to the measurement method rather than the constructs represented by these measures (Podsakoff, MacKenzie, Lee, \& Podsakoff, 2003). It particularly poses a threat to studies where data was collected from a single data source, like ours, and, if ignored, it can potentially bias the relationships among the constructs of interest (Fuller, Simmering, Atinc, Atinc, \& Babin, 2016).

In our study, we used several techniques to minimize the potential effect of CMV. In terms of procedural techniques, we informed respondents about the confidentiality and anonymity of their responses as well as that no right or wrong answers exist. Moreover, it was emphasized to answer honestly. In the design of the survey, we avoided ambiguous and double-barreled questions, and questions were kept concise. These procedural techniques are expected to reduce the effect of CMV (Podsakoff et al., 2003).

In addition to the procedural techniques, we statistically assessed the effect of CMV. Our strategy was two-fold: First, we conducted Harman's single factor test, i.e., extracting a single factor using EFA. The results revealed that a single factor could only explain $36.5 \%$ of the variation in the sample that is below the suggested threshold of $50 \%$ indicating that the degree of CMV is not harmful (Malhotra, Schaller, \& Patil, 2017). As the effectiveness of Harman's single factor test has been criticized (Podsakoff et al., 2003), we additionally employed a post-hoc latent marker approach. In doing so, we followed the guidelines suggested by Williams, Hartman, and Cavazotte (2010), and employed value consciousness as a latent marker variable as price and quality consciousness during shopping is theoretically irrelevant to, and thus, uncorrelated to the other constructs.

The suggested procedure involves several steps. First, the latent marker variable together with its indicators was added to the original CFA model (model CFA). ${ }^{1}$ All constructs were allowed to be freely correlated and all indicators were specified to load only on their

\footnotetext{
1 This model contains 8 latent variables, i.e., compulsive buying, compulsive social media use, technostress, materialism, narcissism, vanity (second-order), physical concern (first-order), physical views (first-order), achievement concern (first-order), achievement views (first-order), value consciousness (marker variable), and their 37 indicators.
} 


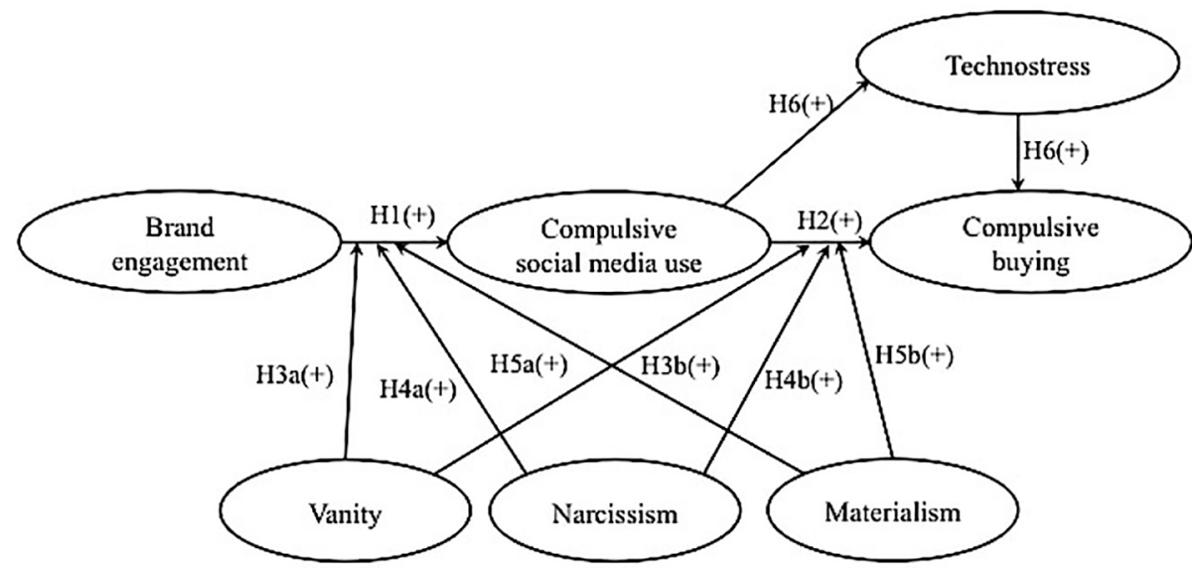

Fig. 2. Research model.

Table 1

Sample characteristics.

\begin{tabular}{llll}
\hline Demographics & Categories & $\mathrm{n}$ & $\%$ \\
\hline Gender & Male & 252 & 47.82 \\
& Female & 275 & 52.18 \\
Age & $18-24$ & 168 & 31.88 \\
& $25-34$ & 179 & 33.97 \\
Education & $35-49$ & 180 & 34.16 \\
& High school or less & 214 & 40.61 \\
& University students & 92 & 17.46 \\
Marital status & University graduates & 152 & 28.84 \\
& Postgraduate or more & 69 & 13.09 \\
Annual income (GBP) & Living without a partner or spouse & 258 & 48.96 \\
& Living with a partner or spouse & 269 & 51.04 \\
& Less than $£ 20,000$ & 231 & 43.83 \\
& $£ 20,000-$ less than $£ 40,000$ & 187 & 35.48 \\
& $£ 40,000-$ less than $£ 60,000$ & 62 & 11.76 \\
& $£ 60,000-$ less than $£ 80,000$ & 17 & 3.23 \\
& More than $£ 80,000$ & 30 & 5.69 \\
\hline
\end{tabular}

respective construct. In a second model (model Baseline), the loadings as well as the variances of the measurement errors of the indicators of value consciousness were fixed to the values obtained from the previous estimation. In addition, the correlations between the latent marker variable and the other constructs were fixed to zero. In a third model (model Method-C), in addition to the restrictions imposed in the model Baseline, all indicators of the substantive constructs were allowed to load on the latent marker variable with equal loadings. This model served the assessment of equal method effects. Subsequently, a fourth model (model Method-U) was estimated, which is similar to model Method-C, but the loadings relating value consciousness with the indicators of the other constructs were not forced to be equal. This allowed for the assessment of unequal method effects. In the fifth and final model (model Method-R), which is similar to model Method-U, the correlations among the substantive constructs were fixed to the values of the Baseline model. This allowed us to assess whether CMV significantly biases the correlations among the constructs of interest.

The results of the different model comparisons are displayed in Table 2. The comparison of the Baseline model with the non-congeneric CMV model (model Method-C) suggested that our dataset is afflicted by CMV. However, the comparison of the non-congeneric CMV model (model Method-C) with the congeneric CMV model (model Method-U) revealed that CMV did not afflict all substantive indicators equally. The standardized loadings of the substantive indicators on the latent marker variable ranged from -0.025 to 0.351 , while the standardized loadings of the substantive indicator on their constructs ranged from
0.663 to 0.844 . Finally, the comparison of the congeneric CMV model (model Method-U) with the restricted model (model Method-R) showed that the presence of the marker variable did not significantly impact and bias the correlations among the substantive constructs in the model. Consequently, we concluded that although CMV is present, its degree did not substantially harm the results of our study. Therefore, in the following analysis the latent marker variable was removed.

\subsection{Measurement model assessment}

To validate our proposed research model, we followed several steps. First, we conducted a CFA to assess the measurement models. The factor model contains the 7 constructs and 33 observable variables and fits the data reasonably: comparative fit index $(\mathrm{CFI})=0.957$, Tucker-Lewis index $(\mathrm{TLI})=0.952$, root mean square error of approximation $($ RMSEA $)=0.042$ (with a $90 \%$ confidence interval $(\mathrm{CI})$ of $[0.0372$; $0.046]$ ), and standardized root mean square residual (SRMR) $=0.0556$. Only the test of exact fit indicated not entirely adequate results, with $\chi^{2}=897.325$, $(\mathrm{df}=470, p<0.01)$. However, this statistic tends to be substantial for larger samples, such as ours (Jöreskog \& Sörbom, 1993), and the difficulty of passing this stringent test is widely acknowledged (Bollen, 1989). Considering Hoelter's critical N, a sample size smaller than 307 observations would have led to a non-significant discrepancy between the empirical and model-implied indicators' variancecovariance matrix. Moreover, all standardized factor loading estimates were significant and ranged from 0.648 to 0.941 .

In the next step, we checked construct reliability, convergent validity, and discriminant validity based on the model without the secondorder construct, i.e., vanity was replaced by its sub-dimensions. As for construct reliability, Cronbach's alpha, and composite reliability (CR) are reported in Table 3. All reliability scores exceeded the suggested threshold of 0.7 . With respect to convergent validity, we calculated the average variance extracted (AVE). All values were above the suggested threshold of 0.5 , and thus were satisfactory. Regarding discriminant validity, Table 3 displays the construct correlation matrix with the square root of the AVE on its diagonal. Although the Fornell-Larcker criterion (Fornell \& Larcker, 1981) indicated that achievement concern and achievement view could not be properly discriminated, following the latest suggestion (Franke \& Sarstedt, 2019), we incorporated the heterotrait-monotrait ratio of correlations (HTMT; Henseler, Ringle, \& Sarstedt, 2015). All values of the HTMT were below the recommended threshold of 0.85 (Franke \& Sarstedt, 2019). Moreover, the corresponding one-sided $99 \%$ percentile bootstrap confidence intervals (499 bootstrap runs) did not exceed 1 , suggesting sufficient discriminant validity. Finally, Table 4 presents the descriptive statistic of the construct scores, i.e., the mean, standard deviation, skewness and excess kurtosis of the average sum scores. 


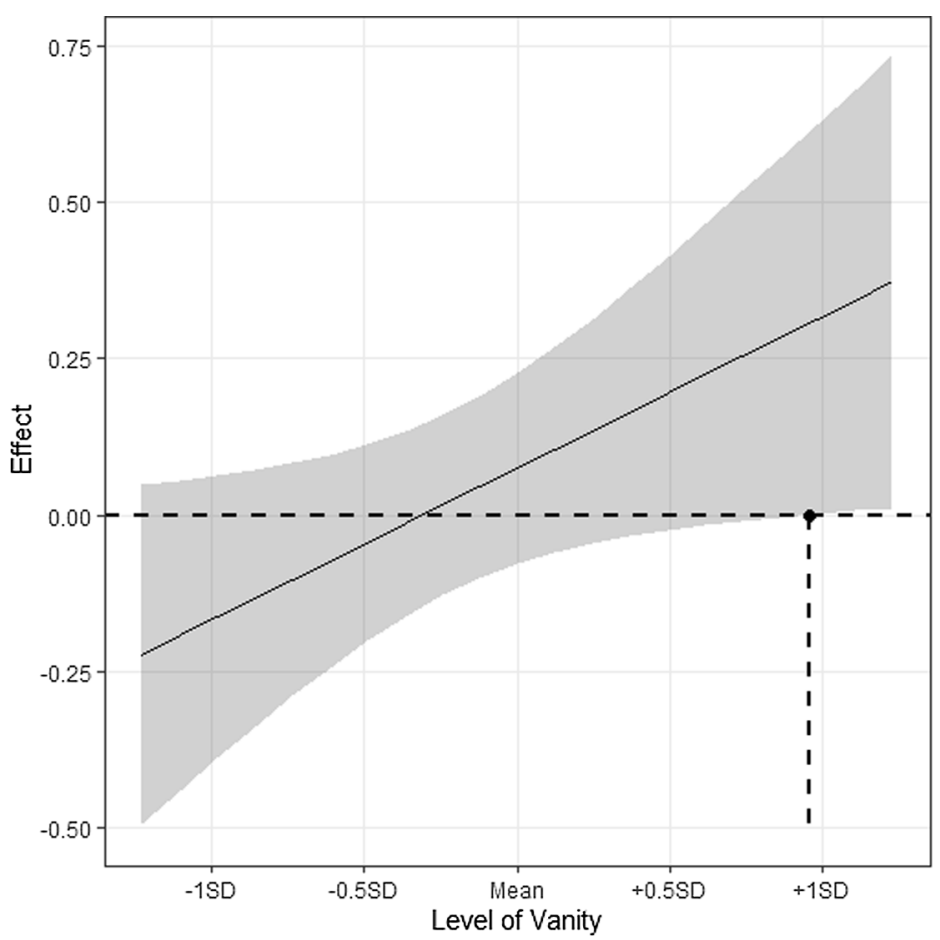

ffect of Brand Engagement on Compulsive Social Mledia Use depending on Vanity

$95 \%$ confidence interval

- Johnson-Neyman point

Fig. 3. Effect of brand engagement on compulsive social media use depending on vanity.

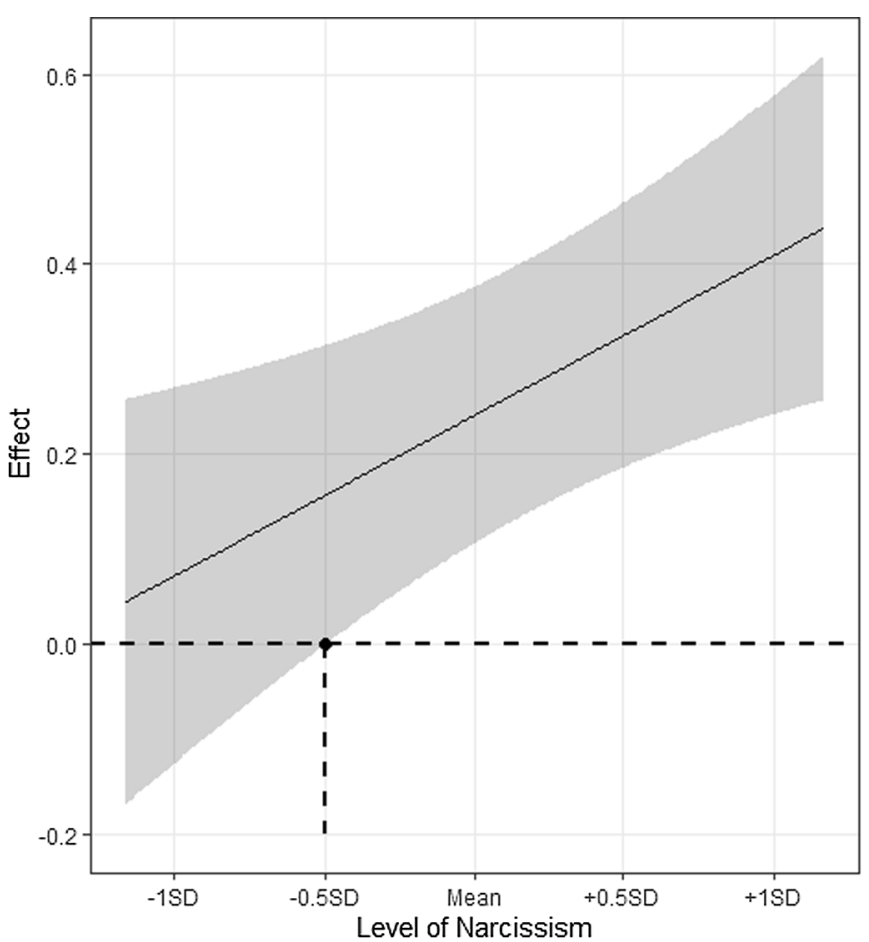

Effect of Compulsive Social Media Us on Compulsive Buying depending on Narcissism

$95 \%$ confidence interval

- Johnson-Neyman point

Fig. 4. Effect of compulsive social media use on compulsive buying depending on narcissism. 
Table 2

Assessment of the effects of common method variance.

\begin{tabular}{|c|c|c|c|}
\hline Model & $\chi^{2}$ & $\mathrm{df}$ & CFI \\
\hline CFA & 1070.313 & 597 & 0.956 \\
\hline Baseline & 1165.730 & 612 & 0.949 \\
\hline Method-C & 1071.652 & 611 & 0.957 \\
\hline Method-U & 1006.809 & 579 & 0.961 \\
\hline Method-R & 1019.273 & 600 & 0.961 \\
\hline$\Delta$ Models & $\Delta \chi^{2}$ & $\Delta \mathrm{df}$ & $\chi^{2}$ Critical value \\
\hline Baseline vs. Method-C & $25.960^{* * *}$ & 1 & 3.841 \\
\hline Method-C vs. Method-U & $64.510^{* * *}$ & 32 & 46.194 \\
\hline Method-U vs. Method-R & 12.778 & 21 & 32.671 \\
\hline
\end{tabular}

Note: Values of the robust statistics are reported.

** $p<0.01$

$\dagger$ alpha $=0.05$.

Table 3

Convergent validity, construct reliability, and Fornell-Larcker criterion.

\begin{tabular}{|c|c|c|c|c|c|c|c|c|c|c|c|c|c|}
\hline \multirow[t]{2}{*}{ Construct } & \multirow[t]{2}{*}{$\alpha$} & \multirow[t]{2}{*}{ CR } & \multirow[t]{2}{*}{ AVE } & \multicolumn{10}{|c|}{ Construct correlations } \\
\hline & & & & 1 & 2 & 3 & 4 & 5 & 6 & 7 & 8 & 9 & 10 \\
\hline 1. Brand engagement & 0.88 & 0.88 & 0.65 & 0.80 & & & & & & & & & \\
\hline 2. Materialism & 0.81 & 0.81 & 0.59 & 0.27 & 0.77 & & & & & & & & \\
\hline 3. Narcissism & 0.85 & 0.86 & 0.67 & 0.25 & 0.44 & 0.82 & & & & & & & \\
\hline 4. Compulsive social media use & 0.92 & 0.92 & 0.74 & 0.19 & 0.31 & 0.44 & 0.86 & & & & & & \\
\hline 5. Technostress & 0.93 & 0.93 & 0.77 & 0.21 & 0.29 & 0.43 & 0.83 & 0.88 & & & & & \\
\hline 6. Compulsive buying & 0.86 & 0.87 & 0.70 & 0.21 & 0.53 & 0.46 & 0.64 & 0.62 & 0.84 & & & & \\
\hline 7. Physical concern & 0.88 & 0.88 & 0.71 & 0.30 & 0.48 & 0.45 & 0.26 & 0.25 & 0.46 & 0.84 & & & \\
\hline 8. Physical view & 0.92 & 0.92 & 0.79 & 0.25 & 0.42 & 0.64 & 0.50 & 0.46 & 0.55 & 0.67 & 0.89 & & \\
\hline 9. Achievement view & 0.90 & 0.90 & 0.76 & 0.29 & 0.32 & 0.68 & 0.45 & 0.47 & 0.49 & 0.50 & 0.68 & 0.87 & \\
\hline 10. Achievement concern & 0.86 & 0.86 & 0.68 & 0.29 & 0.46 & 0.67 & 0.44 & 0.48 & 0.49 & 0.54 & 0.62 & 0.84 & 0.82 \\
\hline
\end{tabular}

Keys: $\alpha=$ Cronbach's alpha, $\mathrm{CR}=$ composite reliability, AVE = average variance extracted.

Note: Bold elements on the diagonal of the construct correlation matrix represent the square roots of the AVE.

Table 4

Descriptive statistics of the average sum scores.

\begin{tabular}{lllrr}
\hline Construct & $\mathrm{M}$ & $\mathrm{SD}$ & \multicolumn{1}{c}{ Skew } & \multicolumn{1}{c}{ Kurt } \\
\hline Brand engagement & 5.17 & 1.16 & -0.75 & 1.09 \\
Materialism & 4.95 & 1.27 & -0.51 & -0.11 \\
Narcissism & 4.37 & 1.45 & -0.40 & -0.43 \\
Compulsive social media use & 2.88 & 1.67 & 0.41 & -1.08 \\
Technostress & 2.90 & 1.74 & 0.48 & -1.02 \\
Compulsive buying & 3.44 & 1.71 & 0.12 & -1.13 \\
Vanity & & & & \\
- Physical concern & 4.90 & 1.39 & -0.73 & 0.31 \\
- Physical view & 4.20 & 1.57 & -0.38 & -0.58 \\
- Achievement view & 4.37 & 1.45 & -0.45 & -0.25 \\
- Achievement concern & 4.26 & 1.48 & -0.39 & -0.42 \\
\hline
\end{tabular}

Notes: $\mathrm{M}=$ mean; $\mathrm{SD}=$ standard deviation; Skew = skewness; Kurt = excess kurtosis.

\subsection{Analysis of direct effects}

Next, we tested our hypotheses by assessing the structural model. Table 5 provides the results for Model 1 , the Baseline model without moderation effects, and Model 2, which contains the interaction terms. ${ }^{2}$ For the linear model, we report the standardized coefficient estimates

\footnotetext{
${ }^{2}$ As a robustness check, we additionally estimated both models including a direct effect of brand engagement on compulsive buying. In both models, this effect was not significant (linear: $\beta_{\text {std }}=-0.033, p=0.417$; non-linear: $\beta=$ $-0.045, p=0.419$ ) and the results were hardly affected. Moreover, the originally proposed linear model did not fit significantly worse $\left(\Delta \chi^{2}=0.6415, p=\right.$ $0.433)$.
}

and for the non-linear model the unstandardized estimates are provided. ${ }^{3}$

Model 1 contains the direct effects of our Baseline research model. The model reasonably fits the data: $\mathrm{CFI}=0.957$, $\mathrm{TLI}=0.952$, RMSEA $=0.042 \quad(90 \% \quad \mathrm{CI}=[0.038,0.046]), \quad \mathrm{SRMR}=0.058, \quad$ and $\chi^{2}=910.178(\mathrm{df}=475, p<0.001)$. Brand engagement had a positive impact on compulsive social media use; however, this effect was not significant at the $5 \%$ level $\left(\beta_{\text {std }}=0.009, p>0.1\right)$, not supporting hypothesis H1. Among the personality traits, i.e., vanity, narcissism, and materialism, only vanity had a positive effect on compulsive social media use $\left(\beta_{s t d}=0.442, p<0.01,\right)$. In total, $29.8 \%$ of the variance in compulsive social media use was explained by Model $1\left(R^{2}=0.298\right)$. At the same time, compulsive social media use had a positive direct effect on compulsive buying $\left(\beta_{s t d}=0.279, p<0.01\right)$, supporting hypothesis H2. Additionally, vanity $\left(\beta_{\text {std }}=0.289, p<0.01\right)$ and materialism $\left(\beta_{\text {std }}=\right.$ $0.283, p<0.01)$ positively affected compulsive buying. Moreover, the results showed that technostress had a positive impact on compulsive buying $\left(\beta_{s t d}=0.195, p<0.05\right)$. In total, Model 1 explained $56.9 \%$ of the variation in compulsive buying $\left(R^{2}=0.569\right)$. Finally, compulsive social media use positively affected technostress $\left(\beta_{\text {std }}=0.832, p<0.01\right)$ and explained $69.3 \%$ of its variance $\left(R^{2}=0.693\right)$

\subsection{Analysis of moderation and mediation}

Next, for Model 1, we investigated the indirect effect of compulsive social media use on compulsive buying. To obtain the inference statistic, we followed the approach suggested by Preacher and Hayes (2008). In doing so, bias-corrected bootstrapping with 10,000 bootstrap runs was

\footnotetext{
${ }^{3}$ MPlus running LMS does not provide standardized estimates in case of interaction terms including endogenous latent variables.
} 
Table 5

Results of the structural model.

\begin{tabular}{|c|c|c|c|c|c|c|c|}
\hline \multirow[t]{2}{*}{ Dependent variable } & \multirow[t]{2}{*}{ Independent variable } & \multicolumn{3}{|l|}{ Model 1} & \multicolumn{2}{|l|}{ Model 2} & \multirow[t]{2}{*}{ Hypothesis testing results } \\
\hline & & $\beta_{s t d}$ & $S E$ & $R^{2}$ & $\beta$ & $S E$ & \\
\hline \multirow[t]{8}{*}{ Compulsive social media use } & & & & 0.298 & & & \\
\hline & Brand engagement & 0.009 & 0.046 & & 0.075 & 0.078 & H1: Partially supported ${ }^{\dagger}$ \\
\hline & Vanity & $0.442^{* *}$ & 0.076 & & $0.927^{* * *}$ & 0.189 & \\
\hline & Narcissism & 0.079 & 0.080 & & 0.061 & 0.107 & \\
\hline & Materialism & 0.068 & 0.053 & & 0.092 & 0.086 & \\
\hline & Brand engagement $\times$ Vanity & & & & $0.298^{*}$ & 0.144 & H3a: Supported \\
\hline & Brand engagement $\times$ Narcissism & & & & -0.050 & 0.096 & H4a: Not supported \\
\hline & Brand engagement $\times$ Materialism & & & & 0.090 & 0.081 & H5a: Not supported \\
\hline \multirow{2}{*}{ Technostress } & & & & 0.693 & & & \\
\hline & Compulsive social media use & 0.832 & 0.023 & & $0.802^{* *}$ & 0.042 & H6: Supported \\
\hline \multirow[t]{9}{*}{ Compulsive buying } & & & & 0.569 & & & \\
\hline & Vanity & $0.289^{* * *}$ & 0.080 & & $0.473^{* * *}$ & 0.138 & \\
\hline & Narcissism & -0.097 & 0.074 & & -0.073 & 0.080 & \\
\hline & Materialism & $0.283^{* *}$ & 0.048 & & 0.348 & 0.064 & \\
\hline & Compulsive social media use & $0.279^{* * *}$ & 0.081 & & $0.241^{* * *}$ & 0.069 & H2: Supported \\
\hline & Technostress & $0.195^{\star}$ & 0.077 & & $0.165^{*}$ & 0.065 & H6: Supported \\
\hline & Compulsive social media use $\times$ Vanity & & & & -0.143 & 0.073 & H3b: Not supported \\
\hline & Compulsive social media use $\times$ Narcissism & & & & $0.131^{* * *}$ & 0.049 & H4b: Supported \\
\hline & Compulsive social media use $\times$ Materialism & & & & -0.056 & 0.042 & H5b: Not supported \\
\hline
\end{tabular}

Note: For LMS no $\mathrm{R}^{2}$ is reported.

${ }^{*} p<0.05$.

$p<0.01$.

$\dagger$ As revealed by the floodlight analysis, only for a high level of vanity, brand engagement has a significant effect on compulsive social media use.

conducted to determine the $95 \% \mathrm{CI}$ of the indirect effect. The results showed that the standardized indirect effect of compulsive social media use on compulsive buying was 0.162 and significant $(95 \% \mathrm{CI}=[0.039$; $0.300]$ ). Since the direct effect of compulsive social media use on compulsive buying remained significant $\left(\beta_{s t d}=0.279,95 \% \mathrm{CI}=\right.$ $[0.112 ; 0.436])$, this finding indicated that technostress complementarily partially mediated the effect of compulsive social media use on compulsive buying (Zhao, Lynch, \& Chen, 2010). The variance accounted for (VAF; Shrout \& Bolger, 2002) was 0.367, showing that $36.7 \%$ of the total effect of compulsive social media use on compulsive buying could be attributed to the mediating effect of technostress, which supported hypothesis $\mathrm{H} 6$.

Model 1 assumes that all individuals function according to the same underlying mechanism. To investigate whether the personality traits (i. e., vanity, materialism, and narcissism) moderate the effects of brand engagement on compulsive social media use and compulsive social media use on compulsive buying, we included the corresponding interaction terms in Model 2.

The magnitude and significance level of the unstandardized effects investigated by Model 1 were very similar for Model 2. The effect of brand engagement on compulsive social media use, if all personality traits were kept at their mean, was not statistically significant $(\beta=$ $0.075, p>0.05$ ), thus not directly supporting hypothesis H1 ${ }^{4}$ Yet, the effect of compulsive social media use on compulsive buying was significant if all personality traits were kept at their mean $(\beta=0.241$, $p<0.01$ ), supporting hypothesis $\mathrm{H} 2$.

To examine the significance of moderation effects, we conducted a floodlight analysis (Spiller, Fitzsimons, Lynch, \& McClelland, 2013). In so doing, we investigated for which level of the moderator, i.e., deviations from its mean, the moderated effect becomes significant. This can be done by examining whether the CI constructed around the moderated effect, which depends on the level of the moderator, covers the zero. The Johnson-Neyman point indicates the intersection, i.e., it is the point where the CI cuts the dashed horizontal zero line. Fig. 3 displays the effect of brand engagement on compulsive social media use for

\footnotetext{
${ }^{4}$ It is important to note that in Model 2, the size of this effect and therefore its significance depends on the level of the personal characteristics. Consequently, at this point no final statement about hypothesis $\mathrm{H} 1$ can be made.
}

different levels of vanity ranging from minus to plus one standard deviation from the mean of vanity. ${ }^{5}$ In doing so, the other two personality traits, i.e., narcissism and materialism, were kept at their mean. The shaded area illustrates the $95 \%$ normal CI constructed around this effect, and the dot depicts the Johnson-Neyman point. As mentioned previously, the effect of brand engagement on compulsive social media use was not significant at the mean of vanity ( $\beta=0.075, p>0.05$ ), as the CI covers the zero at this place. However, the floodlight analysis revealed that the Johnson-Neyman point was 0.9 , i.e., when vanity reached a value of 0.78 (i.e., a value greater than 0.96 times its standard deviation), the effect of brand engagement on compulsive social media use became significant. In other words, the effect of brand engagement on compulsive social media use became stronger for vain individuals ( $\beta=0.298, p<0.05$ ). This finding partially supports hypotheses $\mathrm{H} 1$ and H3a. In contrast, vanity did not moderate the effect of compulsive social media use on compulsive buying ( $\beta=-0.143, p>0.05)$. Thus, hypothesis H3b was not supported.

Although materialism showed an effect on compulsive buying ( $\beta=$ $0.348, p<0.01)$, it did not moderate the effect of compulsive social media use on compulsive buying $(\beta=-0.056, p>0.05)$. Similarly, materialism did not moderate the effect of brand engagement on compulsive social media use $(\beta=0.090, p>0.05)$. Thus, both hypotheses H5a and H5b were not supported.

In contrast, the moderating effects of narcissism were partially observed. While narcissism did not moderate the effect of brand engagement on compulsive social media use $(\beta=-0.050, p>0.05)$, it moderated the effect of compulsive social media use on compulsive buying ( $\beta=0.131, p<0.01)$, supporting hypothesis H4b but not hypothesis H4a. Moreover, a floodlight analysis in Fig. 4 revealed that the effect of compulsive social media use on compulsive buying became significant for values of narcissism larger than -0.5 times its standard deviation, keeping the other two personality traits at their mean. In other words, the effect of compulsive social media use on compulsive buying became stronger for a more narcissistic person, while it was not significant for a less narcissistic person. This additionally supported hypothesis $\mathrm{H} 2$.

\footnotetext{
5 By assumption in LMS, exogenous latent variables such as Vanity and Narcissism have means of zero (Klein \& Moosbrugger, 2000).
} 
Finally, as in Model 1, the results of Model 2 showed a positive and significant unstandardized indirect effect of compulsive social media use on compulsive buying $(0.132, p<0.05)$. This supported hypothesis H6, as technostress complementarily partially mediated the effect of compulsive social media use on compulsive buying, if all personality traits were kept at their mean values $(\mathrm{VAF}=0.354)$.

\section{Limitations}

Before examining the implications of the study, we recognize a few important limitations. First, our sample is limited to UK consumers. In addition, we did not take into account any factors associated with British culture that might have affected Instagram use. Furthermore, we excluded those older than 50 years, due to low Instagram usage. Second, the definition of brand engagement varies, and this study defined brand engagement as part of consumers' self-concept (Sprott et al., 2009). Thus, the results of this study are dependent on this definition and its related context, but it may not be applicable to other brand engagement constructs. Third, this study exclusively examined Instagram users and ignored other types of social media such as Facebook and Twitter. Because of the above, the generalization of the results should be done carefully.

\section{Discussion}

Theoretically, this study opens a new research stream of brand engagement from the perspective of passion - the dual theory of passion had a certain explanatory power for the association between brand engagement and compulsive behaviors. Compulsive behaviors as a dark side of brand engagement make sense in light of obsessive passion and harmonious passion. This is important not only because such a dyad has seldom been contemplated and examined in the past literature, but also because our findings clearly link passion research with engagement research. Perhaps this is the most important contribution of this article.

The examination of three moderators is another novel contribution. First, researchers have examined the relationship between compulsive buying, vanity, narcissism, and materialism (e.g., Harnish \& Bridges, 2015). Second, recent meta-analysis has found a strong correlation between narcissism and social networking behavior in terms of selfpresentations (Gnambs \& Appel, 2017). However, there has been little research that tries to elaborate on such intertwined relationships among three personality traits leading obsessive behaviors. Avoiding an oversimplification, this study found that each of these constructs might play a unique role and thus differ from one another in terms of their moderation on the relationships among brand engagement, compulsive social media use, and compulsive buying.

Having said that, the interpretation of the results is not straightforward. The direct link between brand engagement and compulsive social media use was statistically non-significant. The effect of brand engagement on compulsive social media use becomes significant only when the level of vanity escalates. In other words, highly engaged individuals would not automatically become obsessive users of social media, unless these people possess the key personality trait, that is, vanity. When vanity comes into play, highly engaged consumers may start showing off achievement and appearances associated with the brands. This seems the most interesting finding in this study.

A somewhat similar pattern was observed in the moderating role of narcissism. Compared with materialism, which exhibits no moderation whatsoever, narcissism does moderate the relationship between compulsive social media use and compulsive buying while this direct relationship was also statistically significant. However, while narcissism is the driver that pushes compulsive social media users toward compulsive buying, its role is limited to a catalyst. There is a significant direct influence of compulsive social media use on compulsive buying. This indicates that obsessive passion for self-enhancement (i.e., selfpresentation, self-display) by itself makes people become more obsessed with consumption. We should note, however, that our research used the general narcissism construct without differentiating between vulnerable (sense of insecurity) and grandiose (sense of self-importance) narcissism. Future research should examine the possible distinct effects of the components of narcissism.

In contrast to vanity and narcissism, materialism does not play any role in our predicted moderations. That is, it is not a desire for material possessions that moves people from Instagram to compulsive buying.

Our findings also provide useful knowledge for practitioners. While firms are undoubtedly interested in expanding their marketing efforts through social media, they need to pay closer attention to the "boundary" between harmonious and obsessive behaviors. While "showing off" personal achievement and being proud may be a natural outcome of brand engagement due to vanity, excessively materialistic or narcissistic marketing appeals (especially advertising) may lead to risky obsession. In this vein, it is advisable that firms should focus more on experiential aspects of the brand, rather than material possession. Perhaps, firms should pursue their brand engagement through events and experiences, rather than sales promotion, as the former helps establish a longer-term, emotional relationship with the brand.

From public policy perspectives, firms should consider a preventive strategy against narcissistic and materialistic buying which may end up driving consumers toward unhealthy, obsessive behaviors. In light of our findings the literature, narcissism may motivate compulsive social media users to display grave self-regulatory shortcomings by engaging in compulsive buying. As such, compulsive behaviors are becoming a serious social issue, and social media marketers should avoid such promotional appeals.

By the same token, practitioners may need to think of how to alleviate the technostress of social media users. As this construct acts as a catalyst for the leap from compulsive social media use to compulsive buying, it seems extremely important to provide some remedy to reduce use-related anxiety in social media contexts.

\section{Acknowledgement}

This research has been funded by the Research Incubator Fund (RIF 2017/18) of King's Business School at King's College London. The authors thank the special issue guest editor, Professor Kyung Hoon Kim, for his guidance during the review process, and three anonymous reviewers whose suggestions helped improve and clarify this manuscript.

\section{Appendix A}

Questionnaire items used in this study

(1) Instagram usage questions

Your Instagram profile is:

Public, please provide your handle: Private

How many pictures (on average) do you post per month? Do you post selfies?

Yes

No

When you are taking a picture, do you think about how to get a good one in order to post it and get good feedback (high number of "likes")?

Yes, I am always thinking about how to get a good picture that will get me a lot of "likes."

Sometimes. I do want to get a good picture, although I am not too worried about not getting enough "likes."

Never. I only post things that I want to share without thinking about how many "likes" I will get.

How often do you think about or check your account to see how many likes you get after you post a picture? How many followers do you have (roughly)? 
How many likes do you need to feel your post was successful?

(2) Compulsive social media use (7-point scale; $1=$ never, $4=$ sometimes, $7=$ always)

- How often do you find it difficult to stop using Instagram when you are online?*

- How often do you continue to use Instagram despite your intention to stop?*

- How often do others (e.g., partner, children, parents, friends) say you should use Instagram less?*

- How often are you short of sleep because of Instagram?

- How often do you think you should use Instagram less often?*

- How often have you unsuccessfully tried to spend less time on Instagram?

- How often do you rush through your (home) work in order to go on Instagram?

- How often do you neglect your daily obligations (work, school, or family life) because you prefer to go on Instagram?

- How often do you feel depressed or irritated when you cannot use Instagram?*

(3) Technostress (Beyens et al., 2016)

- I am forced by Instagram to live with very tight time schedules. *

- I am forced to change habits to adapt to new developments on Instagram.

- I have to sacrifice my personal time to keep current on Instagram.*

- I feel my personal life is being invaded by Instagram.

- I do not find enough time to study and upgrade my technology skills on Instagram.

- I am threatened by people with newer Instagram skills.

(4) Brand elicitation

We are interested in your relationship with a brand that you feel very fond of and emotionally attached to. It can be any brand as long as you have a very strong, special bond to it ....... Please think of a brand that you feel emotionally attached to. In the space provided below, please briefly describe what brand it is, how long you have purchased this brand, and why you feel emotionally attached to it.

(5) Brand engagement (Sprott et al., 2009)

- I have a special bond with this brand.*

- I consider this brand to be a part of myself.*

- I often feel a personal connection between this brand and myself.

- Part of me is defined by this brand in my life.

- I feel as if I have a close personal connection with this brand I most prefer.

- I can identify with this brand in my life.

- There are links between this brand and how I view myself."

- This brand is an important indication of who I am.*

(6) Compulsive buying (Ridgway et al., 2008)

- My closet has unopened shopping bags in it.

- Others might consider me a "shopaholic."

- Much of my life centers on buying things.

- I buy things I don't need.*

- I buy things I did not plan to buy.*

- I consider myself an impulse purchaser.*

(7) Vanity (Netemeyer et al., 1995)

Physical concern items

- The way I look is extremely important to me.

- I am very concerned about my appearance.*

- I would feel embarrassed if I was around people and did not look my best.*

- Looking my best is worth the effort.

- It is important that I always look good.
Physical view items

- People notice how attractive I am.

- My looks are very appealing to others.

- People are envious of my good looks.

- I am a very good-looking individual.*

- My body is sexually appealing.*

- I have the type of body that people want to look at.*

Achievement concern items

- Professional achievements are an obsession with me.

- I want others to look up to me because of my accomplishments.*

- I am more concerned with professional success than most people I know.

- Achieving greater success than my peers is important to me.

- I want my achievements to be recognized by others.*

Achievement view items

- In a professional sense, I am a very successful person.

- My achievements are highly regarded by others.

- I am an accomplished person.

- I am a good example of professional success.*

- Others wish they were as successful as me.*

(8) Narcissism (de Bellis et al., 2016)

- Right now, I feel I deserve more than other people do.*

- Right now, I feel I would make a good leader.

- Right now, I feel I am more capable than other people.

- Right now, I feel I am an exceptional person.

- Right now, I feel I can read people like a book.*

- Right now, I feel like looking at my body.*

(9) Materialism (Richins, 2004)

- I like a lot of luxury in my life.*

- Buying things gives me lots of pleasure.

- My life would be better if I owned certain things I don't have.

- I admire people who own expensive homes, cars, and clothes.*

- I'd be happier if I could afford more things.

- It sometimes bothers me quite a bit that I can't afford to buy all the things that I like.*

- I like to own things that impress people.*

Note: We measured all multiple-item scales based on prior research with a 7 -point scale $(1=$ completely disagree, $4=\mathrm{I}$ don't know, $7=$ completely agree)

*Dropped in the final model estimation.

\section{References}

Ackerman, R. A., Witt, E. A., Donnellan, M. B., Trzesniewski, K. H., Robins, R. W., \& Kashy, D. Q. (2011). What does the narcissistic personality inventory really measure? Assessment, 18(1), 67-87.

Aladwani, A. M., \& Almarzouq, M. (2016). Understanding compulsive social media use: The premise of complementing self-conceptions mismatch with technology. Computers in Human Behavior, 60, 575-581.

Alvarez-Milán, A., Felix, R., Rauschnabel, P. A., \& Hinsch, C. (2018). Strategic customer engagement marketing: A decision making framework. Journal of Business Research, 92(November), 61-70.

The American Psychiatric Association. (2017). DSM-5 update: Supplement to diagnostic and statistical manual of mental disorders (5th ed.). Arlington, VA: American Psychiatric Publishing.

Andreassen, C. S., Billieux, J., Griffiths, M. D., Kuss, D. J., Demetrovics, Z., Mazzoni, E., \& Pallesen, S. (2016). The relationship between addictive use of social media and video games and symptoms of psychiatric disorders: A large-scale cross-sectional study. Psychology of Addictive Behaviors, 30(2), 252-262.

Andreassen, C. S., Pallesen, S., \& Griffiths, M. D. (2017). The relationship between addictive use of social media, narcissism and self-esteem: Findings from a large national survey. Addictive Behaviors, 64, 287-293.

Ayyagari, R., Grover, V., \& Purvis, R. (2011). Technostress: Technological antecedents and implications. MIS Quarterly, 53(4), 831-858.

Baker, A. W., Moschis, G. P., Rigdon, E., \& Fatt, C. K. (2016). Linking family structure to impulse-control and obsessive-compulsive buying. Journal of Consumer Behavior, 15 (4), 291-302.

Balon, S., Lecoq, J., \& Rimé, B. (2013). Passion and personality: Is passionate behavior a function of personality? European Journal of Applied Psychology, 63(1), 59-65.

Belk, R. (1988). Possessions and the extended self. Journal of Consumer Research, 15(2), 139-168. 
Bergman, S. M., Fearrington, M. E., Davenport, S. W., \& Bergman, J. Z. (2011). Millennials, narcissism, and social networking: What narcissists do on social networking sites and why. Personality and Individual Differences, 50(5), 706-711.

Bernardi, S., \& Pallanti, S. (2009). Internet addiction: A descriptive clinical study focusing on comorbidities and dissociative symptoms. Comprehensive Psychiatry, 50 (6), 510-516.

Beyens, I., Frison, E., \& Eggermont, S. (2016). "I don't want to miss a thing": Adolescents" fear of missing out and its relationship to adolescents' social needs, Facebook use, and Facebook related stress. Computers in Human Behavior, 64, 1-8.

Billieux, J., Rochat, L., Rebetez, M. M. L., \& Van der Linden, M. (2008). Are all facets of impulsivity related to self-reported compulsive buying behavior? Personality and Individual Differences, 44(6), 1432-1442.

Blachnio, A., Przepiorka, A., Benvenuti, M., Cannata, D., Ciobanu, A. M., Senol-Durak, E., \& Ben-Ezra, M. (2016). Cultural and personality predictors of Facebook intrusion: A cross-cultural study. Frontiers in Psychology, 7, 1895. https://doi.org/10.3389/ fpsyg.2016.01895.

Bollen, Kenneth A. (1989). Structural equations with latent variables. New York, NY: John Wiley \& Sons.

Brodie, R., Hollebeek, L., Jurić, B., \& Ilić, A. (2011). Customer engagement: Conceptua domain, fundamental propositions, and implications for research. Journal of Service Research, 14(3), 252-271.

Buffardi, L. E., \& Campbell, W. K. (2008). Narcissism and social networking web sites. Personality and Social Psychology Bulletin, 34(1), 1303-1314.

Cai, H., Shi, Y., Fang, X., \& Luo, Y. L. L. (2015). Narcissism predicts impulsive buying: Phenotypic and genetic evidence. Frontiers in Psychology, 6, 881. https://doi.org/ 10.3389/fpsyg.2015.00881.

Caplan, S. E. (2003). Preference for online social interaction: A theory of problematic Internet use and psychosocial well-being. Communication Research, 30(6), 625-648.

Caplan, S. E. (2007). Relations among loneliness, social anxiety and problematic Internet use. CyberPsychology \& Behavior, 10(2), 334-342.

Carpenter, C. J. (2012). Narcissism on Facebook: Self-promotional and anti-social behavior. Personality and Individual Differences, 52(4), 482-486.

Chan, T. K. H., Cheung, C. M. K., \& Lee, Z. W. Y. (2017). The state of online impulsebuying research: A literature analysis. Information \& Management, 54(2), 204-217.

Darrat, A. A., Darrat, M. A., \& Amyx, D. (2016). How impulse buying influences compulsive buying: The central role of consumer anxiety and escapism. Journal of Retailing and Consumer Services, 31, 103-108.

Davenport, K., Houston, J. E., \& Griffiths, M. D. (2012). Excessive eating and compulsive buying behaviours in women: An empirical pilot study examining reward sensitivity, anxiety, impulsivity, self-esteem and social desirability. International Journal of Mental Health and Addiction, 10(4), 474-489.

de Bellis, E., Sprott, D. E., Herrmann, A., Bierhoff, H. W., \& Rohmann, E. (2016). The influence of trait and state narcissism on the uniqueness of mass-customized products. Journal of Retailing, 92(2), 162-172.

Faber, R. J., \& Christenson, G. A. (1996). In the mood to buy: Differences in the mood states experienced by compulsive buyers and other consumers. Psychology \& Marketing, 13(8), 803-819.

Faber, R. J., Christenson, G. A., de Zwaan, M., \& Mitchell, J. (1995). Two forms of compulsive consumption: Comorbidity of compulsive buying and binge eating. Journal of Consumer Research, 22(3), 296-304.

Faber, R. J., O'Guinn, T. C., \& Krych, R. (1987). Compulsive consumption. In M. Wallendourf, \& J. Updike (Eds.), Advances in consumer research (pp. 132-135). Provo, UT: Association for Consumer Research.

Fornell, C., \& Larcker, D. F. (1981). Evaluating structural equation models with unobservable variables and measurement error. Journal of Marketing Research, 18(1), 39-50.

Fournier, S. (1998). Consumers and their brands: Developing relationship theory in consumer research. Journal of Consumer Research, 24(4), 343-353.

Franke, G., \& Sarstedt, M. (2019). Heuristics versus statistics in discriminant validity testing: A comparison of four procedures. Internet Research, 29(3), 430-447.

Fuller, C. M., Simmering, M. J., Atinc, G., Atinc, Y., \& Babin, B. J. (2016). Common methods variance detection in business research. Journal of Business Research, 69(8), 3192-3198.

Gnambs, T., \& Appel, M. (2017). Narcissism and social networking behavior: A metaanalysis. Journal of Personality, 86(2), 200-212.

Grisaffe, D. B., \& Nguyen, H. P. (2011). Antecedents of emotional attachment to brands Journal of Business Research, 64(10), 1052-1059.

Harnish, R. J., \& Bridges, K. R. (2015). Compulsive buying: The role of irrational beliefs, materialism, and narcissism. Journal of Rational-Emotive \& Cognitive-Behavior Therapy, 33(1), 1-16.

Henseler, J., Ringle, C. M., \& Sarstedt, M. (2015). A new criterion for assessing discriminant validity in variance-based structural equation modeling. Journal of the Academy of Marketing Science, 43(1), 115-135.

Hollander, E., \& Allen, A. (2006). Is compulsive buying a real disorder, and is it really compulsive? American Journal of Psychiatry, 163(10), 1670-1672.

Hsiao, K. L., Shu, Y., \& Huang, T. C. (2017). Exploring the effect of compulsive social app usage on technostress and academic performance: Perspectives from personality traits. Telematics and Informatics, 34(2), 679-690.

Jöreskog, K. G., \& Sörbom, D. (1993). LISREL 8: Structural equation modeling with the SIMPLIS command language. Lincolnwood, IL: Scientific Software International.

Klein, A., \& Moosbrugger, H. (2000). Maximum likelihood estimation of latent interaction effects with the LMS method. Psychometrika, 65(4), 457-474.

Koran, L. M., Faber, R. J., Aboujaoude, E., Large, M. D., \& Serpe, R. T. (2006). Estimated prevalence of compulsive buying behavior in the United States. American Journal of Psychiatry, 163(10), 1806-1812.
Kukar-Kinney, M., Ridgway, N. M., \& Monroe, K. B. (2009). The relationship between consumers' tendencies to buy compulsively and their motivations to shop and buy on the Internet. Journal of Retailing, 85(3), 298-307.

Kukar-Kinney, M., Ridgway, N. M., \& Monroe, K. B. (2012). The role of price in the behavior and purchase decisions of compulsive buyers. Journal of Retailing, 88(1), 63-71.

Lafrenière, M.-A. K., Vallerand, R. J., \& Sedikides, C. (2013). On the relation between self-enhancement and life satisfaction: The moderating role of passion. Self and Identity, 12(6), 597-609.

Lee, S. B., Lee, S. C., \& Suh, Y. H. (2016). Technostress from mobile communication and its impact on quality of life and productivity. Total Quality Management \& Business Excellence, 27(7-8), 775-790.

Lee, S. Y., Gregg, A. P., \& Park, S. H. (2013). The person in the purchase: Narcissistic consumers prefer products that positively distinguish them. Journal of Personality and Social Psychology, 105(2), 335-352.

Lee, Y. K., Chang, C. T., Lin, Y., \& Cheng, Z. H. (2014). The dark side of smartphone usage: Psychological traits, compulsive behavior and technostress. Computers in Human Behavior, 31(1), 373-383.

Lejoyeux, M., Tassain, V., Solomon, J., \& Ades, J. (1997). Study of compulsive buying in depressed patients. Journal of Clinical Psychology, 58(4), 169-173.

Leung, L. (2013). Generational differences in content generation in social media: The roles of the gratifications sought and of narcissism. Computers in Human Behavior, 29 (3), 997-1006.

Li, J., Lu, M., Xia, T., \& Guo, Y. (2018). Materialism as compensation for self-esteem among lower-class students. Personality and Individual Differences, 131, 191-196.

Mageau, G. A., Vallerand, R. J., Charest, J., \& Salvy, S.-J. (2009). On the development of harmonious and obsessive passion: The role of autonomy support, activity specialization, and identification with the activity. Journal of Personality, 77(3), 601-646.

Mak, B., Nickerson, R. C., \& Sim, J. (2018). Mobile technology dependence and mobile technostress. International Journal of Innovation \& Technology Management, 15(4), 1850039.

Malär, L., Krohmer, H., Hoyer, W. D., \& Nyffenegger, B. (2011). Emotional brand attachment and brand personality: The relative importance of the actual and the ideal self. Journal of Marketing, 75(4), 35-52.

Malhotra, N. K., Schaller, T. K., \& Patil, A. (2017). Common method variance in advertising research: When to be concerned and how to control for it. Journal of Advertising, 46(1), 193-212.

Malik, S., \& Khan, M. (2015). Impact of Facebook addiction on narcissistic behavior and self-esteem among students. Journal of Pakistan Medical Association, 65(3), 260-263.

Marsh, S. (2018). NHS to launch first Internet addiction clinic. The Guardian. Retrieved from https://www.theguardian.com/society/2018/jun/22/nhs-internet-addiction-c linic-london-gaming-mental-health (June 22).

Marshall, T. C., Lefringhausen, K., \& Ferenczi, N. (2015). The Big Five, self-esteem and narcissism as predictors of the topics people write about in Facebook status updates. Personality and Individual Differences, 85, 35-40.

Miltenberger, R. G., Redlin, J., Crosby, R., Stickney, M., Mitchell, J., Wonderlich, S., ... Smyth, J. (2003). Direct and retrospective assessment of factors contributing to compulsive buying. Journal of Behavior Therapy and Experimental Psychiatry, 34(1), $1-9$.

Muthén, L. K., \& Muthén, B. O. (2017). Mplus user's guide (8th ed.). Los Angeles, CA: Muthén \& Muthén.

Netemeyer, R. G., Burton, S., \& Lichtenstein, D. R. (1995). Trait aspects of vanity: Measurement and relevance to consumer behavior. Journal of Consumer Research, 21 (4), 612-626.

O'Guinn, T. C., \& Faber, R. J. (1989). Compulsive buying: A phenomenological exploration. Journal of Consumer Research, 16(2), 147-157.

Pincus, A. L., \& Lukowitsky, M. R. (2010). Pathological narcissism and narcissistic personality disorder. Annual Review of Clinical Psychology, 6, 421-446.

Piquet-Pessoa, M., Ferreira, G. M., Melca, I. A., \& Fontenelle, L. F. (2014). DSM-5 and the decision not to include sex, shopping or stealing as addictions. Current Addiction Reports, 1(3), 172-176.

Podsakoff, P. M., MacKenzie, S. B., Lee, J. Y., \& Podsakoff, N. P. (2003). Common method biases in behavioral research: A critical review of the literature and recommended remedies. Journal of Applied Psychology, 88(5), 879-903.

Porter, G., \& Kakabadse, N. K. (2006). HRM perspectives on addiction to technology and work. Journal of Management Development, 25(6), 535-560.

Preacher, K. J., \& Hayes, A. F. (2008). Asymptotic and resampling strategies for assessing and comparing indirect effects in multiple mediator models. Behavior Research Methods, 40(3), 879-891.

Quinones, C., \& Kakabadse, N. K. (2015). Self-concept clarity, social support and compulsive Internet use: A study of the US and the UAE. Computers in Human Behavior, 44, 347-356.

Quinones-Garcia, C., \& Korak-Kakabadse, N. (2014). Compulsive Internet use in adults: A study of prevalence and drivers within the current economic climate in the UK. Computers in Human Behavior, 30, 171-180.

$\mathrm{R}$ Core Team (2018). R: A language and environment for statistical computing [Computer software manual]. Vienna, Austria. Retrieved from http://www.R-pro ject.org/.

Ragu-Nathan, T. S., Tarafdar, M., \& Ragu-Nathan, B. S. (2008). The consequences of technostress for end users in organizations: Conceptual development and empirical validation. Information Systems Research, 19(4), 417-433.

Richins, M. L. (2004). The material value scale: Measurement properties and development of a short form. Journal of Consumer Research, 31(1), 209-219. 
Richins, M. L., \& Dawson, S. (1992). A consumer values orientation for materialism and its measurements: Scale development and validation. Journal of Consumer Research 19(3), 303-316.

Ridgway, N. M., Kukar-Kinney, M., \& Monroe, K. B. (2008). An expanded conceptualization and a new measure of compulsive buying. Journal of Consumer Research, 35(4), 622-639.

Rindfleisch, A., Burroughs, J. E., \& Wong, N. (2009). The safety of objects: Materialism, existential insecurity and brand connection. Journal of Consumer Research, 36(1), $1-16$.

Rose, P. (2007). Mediators of the association between narcissism and compulsive buying: The roles of materialism and impulse control. Psychology of Addictive Behaviors, 21 (4), 576-581.

Rosen, L. D., Whaling, K., Rab, S., Carrier, L. M., \& Cheever, N. A. (2013). Is Facebook creating "iDisorders"? The link between clinical symptoms of psychiatric disorders and technology use, attitudes and anxiety. Computers in Human Behavior, 29(3), 1243-1254.

Sheldon, P., \& Bryant, K. (2016). Instagram: Motives for its use and relationship to narcissism and contextual age. Computers in Human Behavior, 58, 89-97.

Shrout, P. E., \& Bolger, N. (2002). Mediation in experimental and nonexperimental studies: New procedures and recommendations. Psychological Methods, 7(4), 422-445.

Spiller, S. A., Fitzsimons, G. J., Lynch, J. G., Jr, \& McClelland, G. H. (2013). Spotlights, floodlights, and the magic number zero: Simple effects tests in moderated regression. Journal of Marketing Research, 50(2), 277-288.

Sprott, D., Czellar, S., \& Spangenberg, E. (2009). The importance of a general measure of brand engagement on market behavior: Development and validation of a scale. Journal of Marketing Research, 46(1), 92-104.

Tarafdar, M., Tu, Q., Ragu-Nathan, B. S., \& Ragu-Nathan, T. S. (2007). The impact of technostress on role stress and productivity. Journal of Management Information Systems, 24(1), 301-328.

Vallerand, R. J. (2008). On the psychology of passion: In search of what makes people's lives most worth living. Canadian Psychology, 49(1), 1-13.

Vallerand, R. J. (2010). On passion for life activities: The dualistic model of passion. Advances in Experimental Social Psychology, 42, 97-193.

Vallerand, R. J., Blanchard, C., Mageau, G. A., Koestner, R., Ratelle, C., Léonard, M., .. Marsolais, J. (2003). Les passions de l'âme: On obsessive and harmonious passion. Journal of Personality and Social Psychology, 85(4), 756-767.

van Doorn, J., Lemon, K. N., Mittal, V., Nass, S., Pick, D., Pirner, P., \& Verhoef, P. C. (2010). Customer engagement behavior: Theoretical foundations and research directions. Journal of Service Research, 13(3), 253-266.

Vonkeman, C., Verhagen, T., \& van Dolen, W. (2017). Role of local presence in online impulse buying. Information \& Management, 54(8), 1038-1048.

Warde, A. (2005). Consumption and theories of practice. Journal of Consumer Culture, 5 (2), 131-153.

Weil, M. M., \& Rosen, L. D. (1997). Technostress: Coping with technology @Work@Home @Play. Hoboken, NJ: John Wiley \& Sons.
Wickham, H. (2016). ggplot2: Elegant graphics for data analysis (2nd ed.). New York, NY: Springer.

Williams, L. J., Hartman, N., \& Cavazotte, F. (2010). Method variance and marker variables: A review and comprehensive CFA marker technique. Organizational Research Methods, 13(3), 477-514.

Workman, J. E., \& Lee, S.-H. (2010). Vanity and public self-consciousness: A comparison of fashion consumer groups and gender. International Journal of Consumer Studies, 35 (3), 307-315.

Young, K. (1996). Psychology of computer use: XL. Addictive use of the Internet: A case that breaks the stereotype. Psychological Reports, 79(3), 899-902.

Zhao, X., Lynch, J. G., Jr, \& Chen, Q. (2010). Reconsidering Baron and Kenny: Myths and truths about mediation analysis. Journal of Consumer Research, 37(2), 197-206.

Zilio-Abdala, P. R., \& Vargas-Rossi, C. A. (2008). Vanity and consumption: How physical vanity influences the consumer behavior. In C. R. Acevedo, J. M. C. Hernandez, \& T. M. Lowrey (Eds.), Latin American advances in consumer research (Vol. 2, p. 214) Duluth, MN: Association for Consumer Research.

Shintaro Okazaki is Professor of Marketing at King's College London, UK. He obtained his $\mathrm{PhD}$ from the Autonomous University of Madrid. He is current Editor-in-Chief of the Journal of Advertising. His research focuses on compulsive online behavior, terror management theory, global advertising, and access economy. He has published extensively in leading business journals including Journal of Word Business, Journal of International Marketing, Journal of Interactive Marketing, and Journal of Public Policy \& Marketing, among others. He is former President of the European Advertising Academy.

Florian Schuberth is an Assistant Professor at the Chair of Product-Market Relations of the University of Twente, the Netherlands. He obtained his Ph.D. in Econometrics at the Faculty of Business Management and Economics of the University of Würzburg, Germany. His main research interests lie in Structural Equation Modeling, in particular in compositebased estimators and their enhancement. Florian has published his work in various journals such as Quality \& Quantity, Food Research International, and Internet Research. He presented his work at different conferences, e.g., the International Conference on Computational Statistics.

Takumi Tagashira is Assistant Professor of Marketing at Hitotsubashi University, Japan. He obtained PhD from Kobe University. His research interests lie in retailing, omnichannel management, and consumers' social media usage. Takumi has published in Journal of Interactive Marketing. He also presented his works at several conferences such as European Marketing Academy and Academy of Marketing Science.

Victoria Andrade is a Ph.D. candidate at King's College London, UK. She obtained her M. A. from New York University in Social \& Consumer Psychology. She is also Assistant Professor at Universidad San Francisco de Quito in Ecuador. Her research interests lie in consumer preferences and inner psychological processes during acts of consumption. 